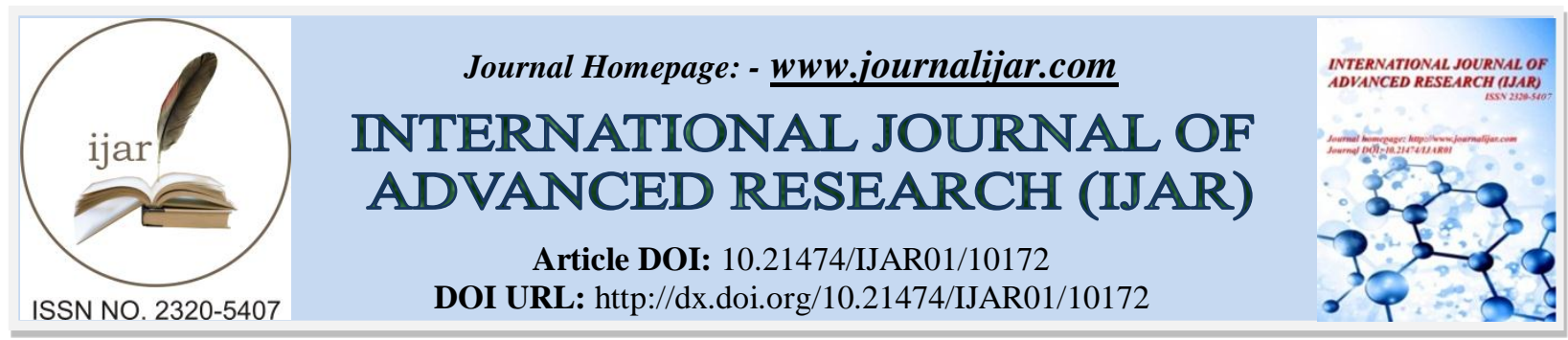

RESEARCH ARTICLE

\title{
COMPOSITE RESINS STRATIFICATION ON ANTERIOR TEETH
}

\section{Pr. Dakkaki J. ${ }^{1}$, Dr. Skalli R. ${ }^{2}$, Pr. Dhoum S. ${ }^{1}$, and Pr. Jabri $\mathbf{M}^{3}$}

1. Assistant Professor, Department of Restorative Dentistry and Endodontics, Faculty of Dentistry, Hassan II University, Casablanca, Morocco.

2. Resident, Department of Restorative Dentistry and Endodontics, Faculty of Dentistry, Hassan II University, Casablanca, Morocco.

3. Professor, Department of Restorative Dentistry and Endodontics, Faculty of Dentistry, Hassan II University, Casablanca, Morocco.

\section{Manuscript Info}

Manuscript History

Received: 05 October 2019

Final Accepted: 07 November 2019

Published: December 2019

Key words:-

Composite, Stratification, Dental Aesthetic, Anterior Restorations, Color, Brightness

\section{Abstract}

The evolution of composite resins stratification on anterior teeth is due to advances in the mechanical and optical properties of these materials. However, to obtain an optimal results, it is necessary to use a rigorous and precise method. This requires an observation of the colorimetric properties of the adjacent teeth. In addition, the use of composite enamel and dentine, combined with a finishing and polishing steps to recreate the internal and external architecture. Once these conditions are met, the practitioner is likely to succeed in a functional restoration similar to the natural tooth.

Copy Right, IJAR, 2019,. All rights reserved.

\section{Introduction:-}

Currently, the search for aesthetics is no longer a wish, but a real requirement that requires dentists to make real changes in our clinical practices. It is shown that when we smile, the oral cavity plays the most important role in the perception of facial aesthetics and that the color of the teeth is one of the concerns of our patients (1). As a result, the main challenge in dentistry is to achieve the best possible color matching between tooth and restoration. This basic criteria is an often complex element to define and to reproduce because the parameters which compose it remain often difficult to analyze $(2,3)$.

Today, the color examination at the dental office is a crucial step that requires extensive knowledge of the optical properties of dental tissue as well as precise knowledge of composite materials. Since the end of the 1990s, they have experienced a significant improvement in their aesthetic potential. Indeed, the products currently on the market are presented with a wide range of colors, luminosities and opacities that allow a better simulation of dentin and enamel. Such developments have allowed practitioners a better control of composite assembly by stratification technique, long perceived by dental surgeons as a complex procedure.

\section{What is the tooth color?}

Color is a communication tool that is part of our daily lives. In conservative dentistry, it is common to talk about color choices. This represents only one dimension of color. It is indeed quite surprising to see that a large number of dentists still work with the Vita Classical shade guide which does not consider all the variation involved in the constitution of the color. Since ancient times painters have defined the first theories of color. In dentistry, the reference is the Munsell chromatic space $(4,5,6)$. This painter, is the first to describe, in 1905, the three-dimensional

Corresponding Author:- Pr. Dakkaki J

Address:- Assistant Professor, Department of Restorative Dentistry and Endodontics, Faculty of Dentistry, Hassan II University, Casablanca, Morocco. 
character of the color. For this purpose, he identified a chromatic circle where all the colors are classified and ordered on a scale.

In this system, the three factors are:

1. The brightness (value) or luminous intensity, it corresponds to the amount of light reflected by an object. This property determines the more or less darkness of the color. It depends essentially on the quality of the enamel, in particular its translucency and its power of light reflection $(2,3,5,6,7)$. Today, it is recognized as the most important factor for a restoration success. According to the Munsell system, brightness is represented on a scale of ten graduations from white to black along the vertical axis (4).

2. The tint (shade), also known as color tone or chromaticity of color. It depends on the wavelength of the light reflected by the object. It allows to distinguish different colored sensations such as red, orange, green and blue. For human teeth, it is in a very limited range between yellow and orange yellow. It is essentially determined by dentin and remains the least important factor in the aesthetic success of a restoration $(2,3,5,6,7)$.

3. Saturation (chroma) is the intensity of the shade, that is, the amount of pure pigment contained in a color. According to the Munsell tree, saturation horizontally increases brightly colored colors, placed at the periphery $(2,3,5,6,7)$.

The dimensions of a tooth :-

Beyond its trichromatic components, the color effect of human teeth depends on several optical factors related to the nature and structure of dental tissues $(5,6)$. Indeed, the optical behavior of the human tooth is very difficult to analyze and uses certain parameters such as translucency, opalescence, fluorescence, surface characteristics and characterizations $(8,9)$.

The study of these parameters leads to a very interesting clinical and practical conclusion: the tissues that constitute the tooth are optically very different. This difference is related to the stratified nature, arrangement, density and size of the mineral crystals of enamel and dentin. Thus, the incident light interacts with the dental organ in different ways.

1. Translucency: it reflects the fact that part of the incident light can pass through an object. This more developed property for enamel is $70 \%$, compared with $40 \%$ for dentin, and is related to the mineral load of the tissue (9, 10). As the translucency of the enamel increases, the brightness decreases. During life, the tooth undergoes structural changes that increase translucency. Thus, the enamel is refined and becomes vitreous, revealing the saturation of the dentin core.

2. Opalescence: this is an optical effect that characterizes the enamel and is reflected by a preferential reflection of the short waves of light, thus manifesting itself in a gray-bluish appearance visible at the incisal edge and the proximal zones, where the enamel does not cover the dentine. While in light transmission, the enamel allows long wavelengths to pass and will produce an orange-red effect $(2,10,11,12)$. This effect, which participates in the natural aspect of the tooth, is observed especially in young subjects, in whom the enamel has not yet been worn.

Fluorescence: reflects the ability of a body subjected to non-visible ultraviolet light to re-emit this energy in the range of the visible spectrum of short wavelength. This characteristic is related to the organic constitution of the dentine. Indeed, collagen contains a pigment sensitive to ultraviolet rays $(2,10,11)$. Thus, it is more marked at the cervical level, where the dentin is the thickest. It is inversely related to saturation and decreases during aging due to the hypermineralization of dentin. Although it is observable only under ultraviolet radiation, it is currently considered an important element for the success of composite restorations $(13,14)$. When a nonfluorescent material is used, it produces a black hole effect and appears greyish under sunlight.

3. Surface characteristics: the color perception is significantly influenced by the surface condition of the tooth as it conditions the reflection of the incident light $(2,5,6)$. Specular reflection occurs when the surface of the material is smooth, that is, there is reflection in only one direction that creates a gloss of the surface. This must be reproduced on the composite restorations, hence the importance of their polishing. This is a good reproduction of dentinal lobes, surface depressions and growth lines of enamel that cause particular light paths.

4. Characterizations: are areas that have a particular color appearance, changing the saturation and brightness of the tooth. We can note the presence of opaque white demineralization spots, brownish spots of fluorosis or even dyschromic enamel cracks that can modulate the translucency of the enamel $(2,5,6,7)$. 


\section{How can the color of a reference tooth be determined?}

Remember that the measurement of the tooth color is a very difficult step, because it is not limited to the choice of a single shade, but corresponds to the evaluation of all the parameters mentioned above. To these difficulties are added other subjective factors $(15,16,17,18)$. Here are the main ones:

1. The disturbing environment: Classically, it is recommended to choose the color of a tooth in the light of a moderately sunny day. However, these conditions can not always be the rule. Thus, the layout of a dental office and its ambient lighting conditions the perception of color. On a practical level, two fundamental rules follow: the incident light must be neither too weak nor too strong, just as it must be close to daylight and capable of restoring all the visible waves so that the tooth can correctly reflect part of the spectrum (19). On the other hand, it should be emphasized that too intense illumination of the operating lights is absolutely not appropriate to differentiate the colors of the teeth. All the teeth examined under the operating light deviate towards an orange component, because it emits a light of average temperature of $3800{ }^{\circ} \mathrm{K}$ and low in the blues $(19,20)$. In addition, the enamel appears more translucent under a light rich in yellows and oranges and thus shows, therefore, a higher saturation and a lower brightness than in reality. Note that in dentistry, researchers recommend using illuminants whose light temperature is between 5000 and $5500^{\circ} \mathrm{K}$, because it is at this temperature, which is that of daylight, that the colors look natural. (20). In the same logic, it is recommended that wall colors or furniture be neutral, such as gray or beige to minimize the variables influencing the perception of colors.

2. Observer: Perception errors are far from marginal and certainly have important clinical implications. Among these, dyschromatopsia affecting about $8 \%$ of men, refractive errors such as myopia and astigmatism, eye fatigue, aging ... are real factors that can lower the quality of the distinction of colors at home. the practitioner. Hence the need to have a regular evaluation of the visual sensitivity. In general, it is recommended to choose the color with the eyes rested, preferably at the beginning of the session in the morning. This act must be fast, being done within 5 to 10 seconds.

3. The patient: Let's say that the eye analyzes the color in comparison with its immediate environment, the colors of clothing or makeup that can be reflected on the teeth must be removed, to minimize the effects of contrast. It should also be noted that the chromatic intensity of the gingiva as well as the absence of adjacent teeth influence the perception of the color of the teeth which will appear whiter.

\section{The means for determining the color:-}

Various shades now exist on the market. The most widespread are coded according to the hue and its saturation. To name just the most used, the Vita Classic classifies the hue into four families designated by the letters A, B, C and D and the saturation by the numbers $1,2,3$ and 4 . This selection method does not consider of the three basic characteristics for choosing the color of the tooth to imitate. For this reason, other dyers have been made available to dental surgeons and which make it possible to make a more reproducible choice of color, giving priority to the determination of the brightness. Some of them, such as the enamel plus HFO or HRi composites, provide superior aesthetic results. These are supplied with a shade guide for dentin and a shade guide for enamel and are made of composite, which allows an adequate correspondence with the optical properties of the future restoration.

However, in spite of the evolution of common shades, the visual determination of the color is a very subjective process in which the control of the different conditions remains very delicate. These limitations explain why current research has led to the creation of innovative devices that provide more reliable, but more complex and costly results. These are measuring instruments such as spectrophotometers and colorimeters that provide color tracking using numerical values. However, they do not allow to appreciate the different characterizations related to the texture and the relief of the tooth. Thus, these new technologies complement the visual method and must be used together to achieve the most appropriate aesthetic result possible.

\section{Currentmaterialsavailable:-}

Since their appearance to the present day, composite resins have evolved, resulting in an improvement of their mechanical and aesthetic qualities. However, the practitioner is entitled to ask the question if these composites lend themselves to all the aesthetic situations at the previous level. To answer this question, many authors have evaluated the results of these restorations in the medium and long term. The conclusion of this research has made it possible to argue that these materials constitute a reliable and economical aesthetic tool, but which will, however, be subject to certain constraints (21). It should be remembered that the main transformations took place within the inorganic phase of the material by increasing the percentage of charges. This has reduced the organic fraction, thereby increasing the fracture and wear resistance and improving the dimensional stability of the material $(22,23)$. 
However, the main evolution lies in the contribution of nanotechnology. The latter allowed the reduction of particle size at the nanometer scale and the modification of their distribution. Indeed, the behavior of particles generated by nanotechnology approaches that of a liquid which allows a greater insertion of the nanoparticles without changing the viscosity of the material. Yap's 2004 study showed that the wear resistance of a nanocharged composite is comparable to or better than that of microfibre and microhybrid composites (24). The explanation lies in the fact that the reduction of the particle size and the increase in their content give lower inter-particle spaces and improve the adhesion to the charge / matrix interface and thus limit the tearing off of the charges. Bharadwaj et al. Have evaluated the wear of a nanocharged composite, a microhybrid and enamel (25).

This study showed that the surface state of the microhybrid composite is worse than that of the nanofilled. This is explained by the fact that the wear would occur by tearing a nanoparticle out of the nanocluster and not by pulling out an entire nanocluster. This mode of wear allows a minimal loss of substance leaving a smoother surface compared to the hybrid composite which has loads of larger size. Thus, the polishing ability has been significantly improved by the provision of nanofillers, which provides better polish retention and reduces hue changes over time.

In addition, the life of composite restorations is directly influenced by the phenomena of solubility and water absorption. Indeed, the composite resins absorb water and release unpolymerized monomers. This phenomenon is at the origin of a decrease of the physical and mechanical properties by a rupture of the link between the matrix and the charges or by a hydrolysis of these last ones. Thus, the composites must be the least soluble possible so that they resist the phenomena of degradation. According to Eick et al. This phenomenon develops essentially within the matrix $(26,27)$. Thus, siloranes are the least soluble monomers. However, Halvorson et al. recommend improving the quality of coupling to prevent the penetration of water molecules and improve stability to hydrolysis (28).

Nowday, clinical evaluations are very few and lead us to remain very attentive when using these products. Indeed, clinical failures remain very high, despite the many improvements in available materials. The latter remain very sensitive to the technique of implementation. Thus, the practitioner is led to rigorously control the steps of the bonding and to respect the indications of each type of material. In addition, regular annual checks to achieve repolishing or even repairs must be integrated into a preventive treatment strategy that will optimize the durability of previous restorations.

\section{The different concepts of stratification:-}

Over the years, we have witnessed an evolution of concepts to achieve aesthetic stratification. This evolution is done in conjunction with the development of composite systems. Indeed, the different techniques described in the literature are differentiated by the number of layers placed in the restoration as a function of the available composite masses. Classically, we distinguish between two- and three-layer concepts. The former requires the placement of an opaque palatal wall to block the light, which is then covered by a buccal layer that reproduces the color of the tooth.

This technique, proposed more than 20 years ago for its simplicity, does not perfectly reproduce the characteristics of the lost tissues and generate restorations with a fixed appearance. Thus, we have moved to three-layer concepts that faithfully replicate the situation of dental tissues (Figs 1 and 2). The palatal face and the proximal crest are restored with enamel masses more or less translucent. The body of the tooth is restored using more or less opaque dentinal masses and decreasing saturations. These masses of composites are called "body dentin". They also exist opaque masses intended to mask dyschromias and the transition zones at the bevel. These dentinal masses will be covered by a vestibular enamel mass whose brightness will be chosen according to age. Specific characterizations can be reproduced by intensive masses of special effects to personalize the restoration. In certain situations, in particular, small cavities or restorations of the incisal edge with small extent, it is useless even an error to want to place too much masses.

Moreover, whatever technique is adopted, special attention is paid to the fracture line. Thus, different approaches have been proposed to hide it. The most common is to make a 1.5 to $2 \mathrm{~mm}$ on the fracture line. Other authors such as Vanini recommend performing a peripheral fillet to ensure a smooth transition and optical continuity between the composite and the enamel (29). This preparation is also essential in order to increase the bonding surface and reduce micro-infiltrations at the composite / tooth seal. On the other hand, finishing and polishing the restoration allows the material to express its intrinsic qualities. This involves creating a surface microgeography, referring to the adjacent tooth, and polishing the material without erasing the details created. For this purpose, the operator can use suitable 
instruments such as diamond-cutters of decreasing granulometry, abrasive discs, grinders and cups ... this step makes it possible to accentuate the flow of light and to get as close as possible to the natural appearance of the tooth.

\section{Conclusion:-}

The success and the integration, as well aesthetic as functional, of the previous restorations in composite resins, are today possible by the materials currently available. Adhesive dentistry has undergone changes that have led to the development of a reliable and reproducible stratification technique. However, the behavior of dental tissues toward the light remains an essential parameter to bypass in order to achieve biomimetic restorations. Moreover, the respect of a precise protocol which does not leave room for the improvisation as well as an annual follow-up in order to repolish or repair the restorations, make it possible to reach an esthetic result which can compete and delay, or even avoid more invasive therapeutic solutions.

\section{Bibliographie:-}

1. Sodagar, Rafatjoo, Borujeni, G., Noroozi, \& Sarkhosh. Software Design for Smile Analysis. Journal of dentistry, 7(4), pp. 170-178.

2. Magne, S., K., Nasr, P., Sharrock, G., Grégoire. Choisir la teinte d'un composite Application au Ceram. X mono. Clinic-Mai 2005- vol. 26 pp. 235-241.

3. Vanini, L. Light and color in anterior composite restorations. Pract Periodont Aesthet Dent 1996 ; 8 : 673-682.

4. Munsell AH. A grammar of color. New York : Van Nostrand Dreinhold, 1969.

5. Lasserre, J-F. Les sept dimensions de la couleur des dents naturelles. Clinic-Juillet 2007- vol. 28 pp. $417-430$.

6. Lasserre, J-F., Pop, I-S, d'Incau E. La couleur en odontologie : Détermination visuelles et instrumentals. $1^{\text {ère }}$ partie. Cah Prothèse $2006 ; 135: 25-39$.

7. Vanini, L., Francesco, M., Mangani, MDT. Determination and communication of color using the five color dimensions of teeth. Pract Proced Aesth Dent 2001; 13 : 19-26.

8. Ahmad, I. Three-dimensional shade analysis: perspectives of color - Part I. Pract Periodont Aesthet Dent 1999;11(7):789-796.

9. Chu, S-J., Devigus, A., Mieleszko, A. Fundamentals of color: shade matching and communication in esthetic dentistry. Tokyo : Quintessence Publishing, 2004.

10. Sieber, C. Motivation. Albbruck (Allemagne) : Vita Siggset print \& media AG, 2005.

11. Chiche, G., Pinault, A. Esthétique et restauration des dents antérieures. Paris : Cdp, 1994.

12. Genini, P., Pinault, A. Etude de l'effet opale de la dent naturelle à la céramo-métallique. Inf Dent. 1990,41 : 3929-3936.

13. Dietchi, D. Free hand composites resin restoration : a key to anterior aesthetics. Pract Periodont Aesthet Dent $1995: 715-725$.

14. Ten Bosh, J-J, Zup, J-R. Optical properties of dentin. In : Thylstrup A, Leach SA, Qvist V. Dentine and dentine reaction in the oral cavity. Oxford : IRL Press, $1987: 59-65$.

15. Preston, J-D. Current status of shade selection and color matching. Quintessence Int 1985;1:47-58.

16. Sproull, R-C. Colour matching in dentistry. Part III. Colour control. J Prosthet Dent 1974;31(2):146-154.

17. Miller, L-L. Shade selection. J Esthet Dent 1994;6:47-60.

18. Miller ,L-L. Shade matching. J Esthet Dent 1993;5:143-153.

19. Zyman, P., Jonas, P. Le choix de la teinte ... Vers un protocole rationnel. . Réalités Cliniques Vol. $14 \mathrm{n}^{\circ} 4$, 2003 pp. 379-392.

20. Lee, Y-K., Yu, B., Lim, J.-I., \& Lim, H.-N. (2011, February). Perceived color shift of a shade guide according to the change of illuminant. The journal of prosthetic dentistry, 105, 91-99.

21. Berthault, G.N., Durand, A.L., Lasfargues, J-J., Decup, F. Les nouveaux composites : évaluation et intérêts cliniques pour les restaurations en technique directe. Rev Odont Stomat 2008;37:177-197.

22. Raskin, A., Salomon, J. P., Sabbagh, J. Les résines composites: classification - évolution. Réal Clin 2005;16:297-312.

23. Raskin, A., Tassery, H., Salomon, J-P. ,Sabbagh, J. Les résines composites: propriétés et indications cliniques. Réal Clin 2005;16:313-326.

24. Yap, A-U, Tan, C-H., Chung, S-M. Wear behavior of new composite restoratives. Oper Dent 2004;29 : 269274.

25. Bharadwaj, P., Lambrechts, P., DE Munck, J., Mattar, D., Van Meerbeck, B. Clinical Wear Performance of Filtek Supreme and Z 100 in Posterior Teeth. IADR 2005;Abstract 0576. 
26. Eick, J-D, Kostoryz, E-L., Rozzi, M., Jacobs, D-W., Oxman, J-D., Chappelow, C-C., Glaros, A-G., Yourtee, DM. In vitro biocompatibility of oxirane/polyol dental composites with promising physical properties. Dent Mater 2002;18: 413-421.

27. Eick, J-D., Smith, R-E, Pinzino, C-S., Kostoryz, E-L. Stability of silorane dental monomers in aqueous systems. J dent 2006; 34:405-410.

28. Halvorson, R-H., Erickson, R-L., Davidson, C-L. The effect of filler and silane content on conversion of resinbased composite. Dent Mater 2003; 19:327-333.

29. Vanini, L., De Simone, F., Tammaro, S. Indirect composite restoration in the anterior region: a predictable technique for complex cases. Pract Periodontics Aesthet Dent 1997;9:795-802.

30. Kuhn, G., Colon, P. Composites antérieures : Techniques de stratification simplifiées. Réalités Cliniques Vol. $14 \mathrm{n}^{\circ}$ 4, 2003 pp. 409-421.

31. Portalier, L. Stratification naturelle des composites antérieurs d'une méthode nouvelle et de son application. Réalités Cliniques Vol. 9 n³, 1998 pp.315-327.

32. Weisrock, G., Koubi, S., Tassery, H. Les résines composites en technique directe : étapes clés. Réalités Cliniques Vol. 24 n 4, 2013 pp. 291-298.

33. Chafaie, A., Kling, C. Evolution des résines composites de restauration sur le plan esthétique. Clinic-Juillet 2007- vol. 28 pp. 463-471.

34. Lehmann, N. Composite antérieur et stratification. Clinic-Avril 2005- vol. 26 pp. 191-197.

35. Lehmann, N., Tirlet, G. Utilisation des composites à vocation esthétique en pratique généraliste. Clinic-Juin 2007- vol. 28 pp. 359-367. 